\title{
Continuance intention to use digital payments in mitigating the spread of COVID-19 virus
}

\author{
Singha Chaveesuk ${ }^{\mathrm{a}}$, Bilal Khalid ${ }^{\mathrm{a} *}$ and Wornchanok Chaiyasoonthorn ${ }^{\mathrm{a}}$
}

${ }^{a}$ KMITL Business School, King Mongkut's Institute of Technology Ladkrabang, Bangkok, Thailand

\begin{tabular}{l}
\hline C H R O N I C L E \\
\hline Article history: \\
Received: June 22, 2021 \\
Received in revised format: Sep- \\
tember 21, 2021 \\
Accepted: November 20, 2021 \\
Available online: November 22, \\
2021 \\
Keywords: \\
COVID-19 \\
Digital payments \\
Contagious diseases \\
Continuance intention \\
Thailand
\end{tabular}
A B S T R A C T

\begin{abstract}
This study investigated the continuous intention to use digital payment solutions in online transactions to mitigate the spread of the COVID-19 virus. Primary data was collected from individuals using digital payment systems in Bangkok, Thailand using a structured questionnaire from a total of 400 respondents. The study adopted the Technology Acceptance Model (TAM). Data were analyzed using Confirmatory Factor Analysis (CFA) and Structural Equation Modeling (SEM) in AMOS 26. The results revealed that factors that significantly affected continuous intention to use digital payments were perceived ease of use, satisfaction, attitude, and social distancing. Satisfaction mediated the effects of perceived usefulness, perceived ease of use, and social distancing on continuous intention to use. Attitude mediated the effect of perceived usefulness on continuous intention to use. The study recommends that concerned policymakers and institutions should consider users' satisfaction, social distancing, and perceived ease of use when developing digital payment systems.
\end{abstract}

(C) 2022 by the authors; licensee Growing Science, Canada.

\section{Introduction}

The advent of technological disruption in the recent past led to changes in the way people work as well in the management of financial transactions and payments. Advancements in technology had a significant impact on businesses, especially the small and medium-sized retail businesses, introducing newer services such as e-commerce. Altounjy et al. (2020) opined that mobile device have become the favored technology that the public looks up to in an aim to enhance and advance their working and personal life goals, and these have become integrated into digital payment methods, while 4.0 technologies and electronic commerce have been seen as instrumental to performance (Nathan et al., 2019; Ślusarczyk et al., 2020). Traditional payment methods, including cash and cheque, became slow-paced in meeting the needs of e-commerce, necessitating the need to develop and grow new digital payment methods. Digital payments involve transactions through digital platforms to exchange money. The process of digital payment occurs when the parties involved in financial transactions use electronic mediums without being physically present at the same place (Hsu et al., 2015). Thailand has experienced phenomenal growth in digital payments in the recent past, which has led to increased financial inclusion among the retail industry. The increased growth of digital payments in Thailand resulted from the increased development of the e-commerce market in the country driven by competition among businesses to increase sales. The share of digital payment volumes in Thailand continues to increase among SME retailers, with future digital transactions expected to constitute half of the retail transactions in the country by 2024. The common digital payment methods include the use of automated teller machines (ATMs), mobile banking, and point of sale (POS) (Muangmee et al., 2021). Various factors contribute to the growth in the adoption of digital payments. For instance, technological advancements leading to the increased use of smartphone technologies significantly influence the increased use of digital payments of the recent past (Baber, 2020). Inferring to Ray et al. (2019), smartphone penetration in 2019 was estimated at $72 \%$ of the population in Thailand. The high smartphone consumption rate in the country offers endless

* Corresponding author.

E-mail address: khalidb9998@gmail.com (B. Khalid)

(C) 2022 by the authors; licensee Growing Science, Canada. doi: $10.5267 /$ j.ijdns.2021.12.001 
opportunities in e-commerce and consequently contributes to the increased adoption of digital payments in the country. Also, the advancements in technology have led to new opportunities for economies to thrive. New government regulations promoting sustainable growth through digital economies have also been significant in influencing the adoption of digital payments in the retail sector. In Thailand, the government is keen on reviewing current policies towards the adoption of new technologies such as the fifth generation Telecommunication network (5G), significant in increasing the country's competitiveness. Similarly, the adoption of digital currency has been contributed by its ability to revolutionize the financial sector, benefiting retail services in various ways. Digital payments offer appealing features such as instant payments that are much faster than the traditional methods through cash and cheques. Digital payments are considered customer-friendly, convenient, and fast, not characterized by traditional payment methods.

Digital payments have been critical to the retail sector during the COVID-19 pandemic period and have contributed to its adoption across the globe. The widespread lockdowns instituted by different governments and limitation of travels confined consumers to their households, necessitating the need to navigate through websites to make purchases. The changes led by the COVID-19 outbreak had significant impacts on the retailers, who in turn embraced e- commerce and digital payments to keep up with the changing consumer behaviors. Although digital payments were being embraced before the advent of the Covid-19 pandemic, the use of e- commerce and digital payments was not balanced. In China, for instance, the use of digital payments was estimated at $56 \%$ pre-pandemic compared to $23 \%$ in the US during the same period (Ray et al., 2019). In Thailand, the outbreak of the COVID-19 pandemic led to the acceleration of digital payments in the retail sector. The need for digital payments during the COVID-19 period in Thailand was pushed by the consumer habits of not wanting to touch cash as a measure of preventing the spread of the coronavirus. Some of the methods used in digital payments in Thailand include the 2C2P payment platform that integrates the local and international payment providers as well as the card schemes and financial institutions. Other methods include the Bangkok Payment Solutions (BPS), Pay Solutions, and SiamPay, Rabbit Card and they all offer secure electronic payments. However, despite the increased growth in digital payment technologies, the rate of adoption across the globe and especially in developing countries has been modest. The rate of adoption in some Asian countries, such as India \& Pakistan, remains low despite the government's efforts to promote its adoption. Increased digital adoption is vital in promoting the growth of the retail sector of the economy. According to Yang et al. (2021), business entities' adoption of digital payments is both inexpensive and feasible. Thus, the possibilities of low adoption rates in digital payments are associated with demand. Promoting the increase in digital payments will thus require an understanding of the consumer's needs and concerns on paying through digital platforms. Based on this background, this study will investigate the continuance intention to use Digital Payments in Thailand to avoid contracting contagious diseases and mitigating the spread of COVID-19 virus.

\section{Literature Review}

Similar to other technological innovations, various factors influence the adoption of digital payment technologies. The intention to adopt digital payments involves individuals' tendency to adopt transactions through electronic mediums (Muangmee et al., 2021). The growth in e-commerce and consequently the increased adoption of digital payments has largely been influenced by the availability of infrastructure to increase the rate of transactions between the involved parties. Ferreira et al. (2020) recognizes that online retailing which depends wholly on digital payments is predominantly driven by early adopters to the technology, usually from the lower income consumer bracket. They add that consumers from the higher-income group pay more attention to the information quality on the business website, while consumers from the lower income group prioritize the significance of order fulfilment. According to Ray et al. (2019), the global growth in the use of digital payments has been on the increase in the recent past, with global use estimated at $51 \%$. However, the rate of adoption between countries is not even, with the US digital transactions rate estimated at 23\% in 2019. Lin, Lin and Ding (2020) attribute the continued adoption of digital payments to benefits such as high security in payment. Users are secure in using digital payments as it records proof of payment, thus limiting cases of fraud. Similarly, digital payments offer better customer convenience where they can make purchases beyond their financial limit and can be able to pay for goods and services bought on credit later. However, using digital payments also comes with various limitations, including inconveniences in cases of network disruptions and other technical glitches. Also, the service fees charged by the payment gateways make purchases through digital payments higher compared to the traditional methods of payments through cash and cheques.

In the recent past, various studies have been conducted to determine the factors influencing the adoption of the new digital payment methods among consumers. For instance, Vinitha and Vasantha (2017) articulate that the adoption of digital payments largely depends on the security and trust of the customers in the technology sector. E-payments involve financial transactions over electronic mediums that do not involve physical money. The use of the electronic payment presents a perception of risk that influences the rate of adoption among the consumers. It is thus an unavoidable fact that although e-payments have been widely adopted around the globe, the perception of risk through the electronic mediums used influences the full adoption of digital payment technologies. Accordingly, the study by (Najib \& Fahma, 2020) aimed to determine the intention of Small and Medium Enterprises (SMEs) to adopt digital payments. In the study, the authors highlighted the aspect of trust as one of the driving factors influencing retailers' intention to use particular digital payments. SMEs have a high liquidity flow, and the feelings of delays in collecting money through digital payments through unstable digital connections are a concern that influences the adoption of digital payment methods.

The review by Patil, Rana and Dwivedi (2018) was conducted to understand the antecedents of digital payment adoption. While studies on the intention of technological use had been conducted on developed countries, limited research had been 
done on developing countries. In the study, the authors pointed out that the continuance intention to use new technologies in digital payments was based on the Technology Acceptance Model (TAM) construct, and a similar instance can be found in Chaveesuk, Khalid and Chaiyasoonthorn (2021); Chaveesuk, Khalid and Chaiyasoonthorn (2020). Based on the Technology Acceptance Model, the individuals' intention to use new technologies is often influenced by the ease of use and the perceived usefulness of the technologies (Khalid et al., 2021; Muangmee et al., 2021). In this case, the intention to use digital payment methods by the retail customers is influenced by the ease of use of these technologies and the extent of usefulness to the customers intending to use the technologies. Also, in the study by Jaradat and Al-Mashaqba (2014), the use of mobile payments and their adoption can be understood using the Technology Acceptance Model. They stated that the anticipation of the users' behavioral intentions can be influenced by the perceived ease of use and other external perceptions, including the image and output quality of the technologies. There are promised growth in digital payments where the users indicate the willingness to purchase and use smartphones.

According to Al-Qeisi et al. (2014), the UTAUT model has various constructs that determine consumers' intentions to use a particular technology and the subsequent usage behavior. The constructs include social influence, behavior intentions, effort expectancy, and performance expectancy of the technologies. The outbreak of the COVID-19 pandemic greatly influenced digital payment technologies. Consequently, the aftermath of the COVID-19 pandemic necessitated the growth in e-commerce. In the study by Mondego and Gide (2020), the scholars acknowledged the role of technology usage and behavior in influencing digital payments' growth. For example, many individuals affected by movement regulations imposed by governments to curb the spread of the virus expected technology to improve their experiences in shopping for basic needs, including food. Muangmee et al. (2021) in analyzing the role of Food Delivery Apps (FDAs) played an important role during the pandemics helping businesses to manage deliveries during the lockdown periods. The intention of use of the Food Delivery Apps (FDAs) was influenced by the technologies' abilities to meet the expectancy of the consumers and the increased perceived trust in the apps to reduce the spread of the virus. The increased usage of digital payments as a consequence of increased use of the FDAs can be associated with the constructs of safety and usage under the Unified Theory of Use and Acceptance of Technology (UTAUT).

Findings from various studies outline the elements of the availability of digital payment tools in the determination of the intention to use the new technologies (Altounjy et al., 2020; Lanlan, Ahmi \& Popoola, 2019; Ray et al., 2019; Zhao \& Bacao, 2020). Advancements in digital payments are largely due to the availability of digital payment tools such as mobile Points of Sales (mPOS) that use applications to process payments. Contactless payments such as Venmo, PayPal, Google Pay, among other tools, and social media payment options such as Facebook pay (Ray et al., 2019). With reference to Lanlan et al. (2019), users' decision to use particular digital payments is greatly influenced by the availability and the users' understanding of the payment tools. Users with a high adoption rate of the technology devices such as smartphones are likely to have a greater understanding of how mobile payments work and can use them to make purchases on various e-commerce platforms. Developments in technology and the increase in the adoption of the new technologies lead to an increase in the users' experiences in digital payments which in turn lead to increased trust and positive behavioral intentions to use the available digital payments. Similarly, improvements in technologies such as the fourth generation and fifth- generation mobile devices led to the improvement in the user experiences through routine likely to produce the relevant impacts on the behavioral intentions for users to adopt the digital payments (Lanlan et al., 2019).

Altounjy et al. (2020) in their study found that perceived usefulness has a significant positive impact on mobile payment acceptance, while the perceived ease of use has no significant impact on the merchants' decision to offer this payment method, which is not compatible with the technology acceptance model (TAM). Under the Technology Acceptance Model concept, the convenience of the new technology plays a vital role in determining the intention to adopt digital payments. In support, Zhao and Bacao (2020) acknowledged the importance of perceived usefulness which indicates the degree of convenience of the use of technology to solve a problem. Thus, if the users find the technology useful in meeting their needs, they could consider it convenient, which could improve the users' intention to use the new technologies. For example, in the advent of the COVID-19, many individuals affected by the lockdown regulations found the use of food delivery apps convenient in the adherence to the regulations protocols and minimizing the spread of the coronavirus (Zhao \& Bacao, 2020). The intention to use digital payments during the covid-19 pandemic was largely influenced by the convenience of the new technologies to meet basic needs such as the purchase of food. Likewise, the intention to use digital payments is also largely influenced by other factors, including regulation policies that affect social trust. Government policies play a role in the social decisions on payment methods. According to Lin et al. (2020), government regulations that determine the implementation of technological innovations often have a negative impact on the consumers' intention to use the technological innovations due to a lack of social trust. Often, centralized governments have centralized decision-making processes that reduce the trust between stakeholders and users. An example involves the government policy by the Indian government to remove about $86 \%$ of its cash from the circulation of banknotes in 2016 (Aleem, 2016; Doshi, 2016). While the decision was aimed at the country's demonetization economic policies, it had profound effects on the people's lives, who in turn sought alternative payment methods due to a lack of trust in the government policies. Consumer trust forms the base of the continued intention to use digital payments by the users. Mondego and Gide (2020) stated that personal aspects also influence the intention to use new technologies. For example, the demographic profiles of individuals play a vital role in the decision to use new technologies. For instance, age has a significant role in the way individuals use new technologies. The younger population tends to be more tech-savvy and likely to use digital payment technologies compared to the older populations in society. 


\section{The Study Model}

The literature review on the continuance intention to using digital payments to avoid contracting contagious diseases and mitigating the spread of COVID-19 led to the development of the study's conceptual framework. The Conceptual Framework was used to guide the study and is presented in the Fig. 1.

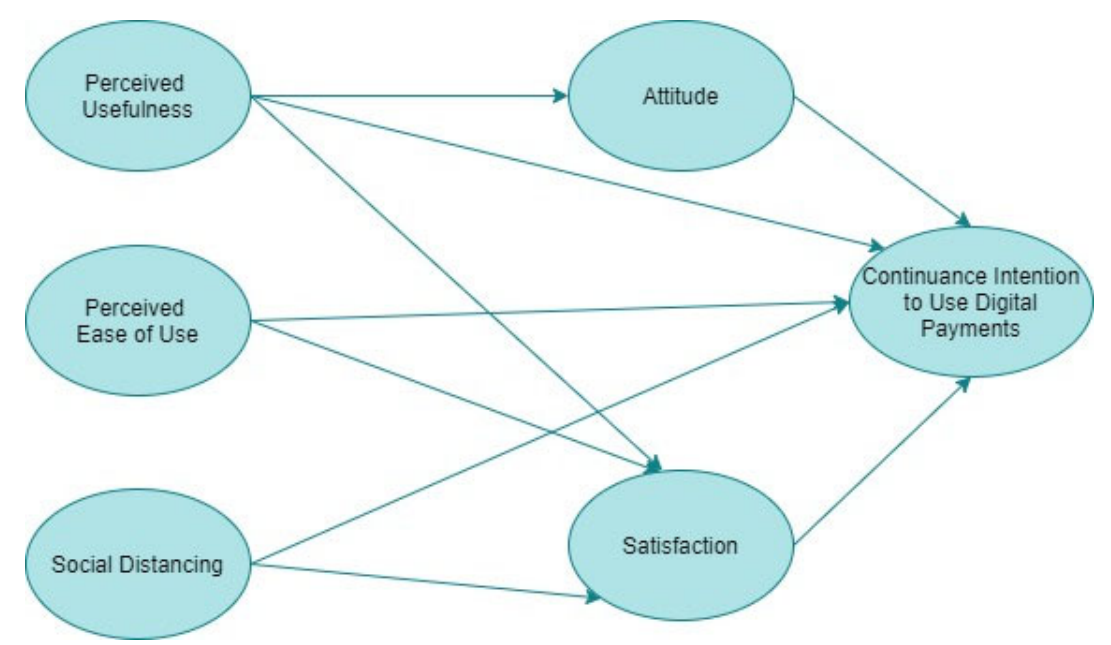

Fig. 1. Conceptual framework

From the conceptual model, various independent variables will be utilized in the research, including; Perceived Usefulness (PU), Perceived Ease of Use (PEU), Social Distancing (SD), Satisfaction (SA), Attitude (ATT) and Continuous Intention (CI). Among the variables, Continuous Intention to use (CI) was the independent variable, and the mediating variables in the framework model were culture and satisfaction. The following hypotheses were developed.

$\mathbf{H}_{1}$ : Perceived usefulness (PU) has a positive influence on the continuous intention to usedigital payments.

H2: Perceived ease of use (PEU) has a positive influence on the continuous intention touse digital payments.

$\mathbf{H}_{3}$ : Social Distancing (SD) has a positive influence on the continuous intention to usedigital payments.

$\mathbf{H}_{4}$ : Attitude (ATT) has a positive influence on the continuous intention to use digitalpayments.

H5: Satisfaction (SA) has a positive influence on the continuous intention to use digitalpayments.

H6: Attitude moderates the relationship between perceived usefulness and continuousintention to use.

$\mathbf{H}_{7}$ : Satisfaction moderates the relationship between perceived usefulness, perceived easeof use social distancing and continuous intention to use.

\section{Methodology}

The study was to investigate the continuance intention to use digital payments in controlling the spread of COVID-19 and other contagious diseases, this study adopted the Technology Acceptance Model (TAM) and modified it to include other variables relevant to the study situation. The variables and the model were discussed in the previous section. The continuance intention (variable of interest) was defined as the level of an individual's intention to make repeated purchases using digital payment systems. Data was collected from a structured questionnaire having questions on each of the study constructs. The responses on each of the constructs were measured using a five-point Likert scale ranging from 1 (strongly disagree) to 5 (strongly agree). The pretest of the questionnaire was made with 15 respondents, who did not participate in the final survey. This helped in exploring the language and typing errors. Purposive sampling technique was adopted to identify respondents who were using the digital payment systems in their retail purchases and transactions. The digital payment systems that were considered for the interview included mobile payments, internet banking payments, debit, and credit card payments, and point of sale (POS) payments. Four experienced interviewers conducted face-to-face interaction with the respondents in Bangkok city. The respondents were approached during the day when carrying out their daily business activities. The data was collected in between March 5, 2021, and May 30, 2021. Out of the 534 valid responses that were given, the final sample considered suitable for the study was 400 resulting in an average response rate of $75 \%$.

The data was analyzed using several techniques. The first technique was the descriptive statistics of the demographic information of the respondents (age, gender, occupation status and income). The reliability and validity of the study constructs were evaluated using Cronbach's Alpha, Convergent Reliability (CR) and Average Variance Extracted (AVE). The study 
model was evaluated using the Confirmatory Factor Analysis (CFA), while the research hypothesis was evaluated using the Structural Equation Modeling (SEM).

\section{Results}

The first analysis conducted was the descriptive statistics which evaluated the characteristics of the respondents. From the gender results, $37 \%$ were male while $63 \%$ were female. Regarding the age of the respondents, the largest proportion were those aged between 20-30 years (54\%), followed by those aged below 20 years of age $(20.8 \%)$ and then those aged between $30-40$ years $(17 \%)$ and lastly those aged $40-50$ years. Considering the occupation variable, the majority of the respondents were those who were company employees $(38 \%)$ followed by those who were students (35\%). The least common occupation among the respondents was self-employment. Another variable that was evaluated was the monthly income of the respondents. The highest income level was below 15000 THB (31\%) followed by those earning 15,001 to 20,000 THB per month. The least income category was those earning above 50,000 THB. The reliability and validity of the analysis were conducted using three measures; Composite Reliability (CR), Average Variance Extracted (AVE) and correlation analysis of the study constructs.

Table 1

Composite Reliability and Average Variance Extracted

\begin{tabular}{lllllllll}
\hline & CR & AVE & ATT & PU & PEU & SA & CI \\
\hline ATT & 0.862 & 0.556 & 1 & & & & & \\
PU & 0.89 & 0.618 & 0.661 & 1 & 1 & 1 & \\
PEU & 0.872 & 0.578 & 0.733 & 0.758 & 0.716 & 0.764 & & \\
SA & 0.886 & 0.608 & 0.786 & 0.698 & 0.787 & 0.825 & \\
CI & 0.897 & 0.636 & 0.747 & 0.793 & 0.796 & 0.812 \\
SD & 0.839 & 0.511 & 0.833 & 0.753 & 1 \\
\hline
\end{tabular}

According to Fornell and Larcker (1981), the convergent reliability threshold should be greater than 0.7 and the average variance extracted (AVE) should be equal to or greater than 0.5. the results presented in the table above shows that all the values of CR and AVE satisfy Fornell and Larcker (1981) threshold, confirming the reliability and validity of the study constructs. The table also shows the correlation analysis of the study variables. It was critical to evaluate the fitness of the model using the confirmatory factor analysis (CFA). In the testing of the model efficacy, the indices used were comparative fit index (CFI), goodness-of-fit index (GFI), normed fit index (NFI), Tucker-Lewis Index (TLI), chi-square $\left(\chi^{2}\right)$ and $\chi 2 / \mathrm{df}$. The model below shows CFA reflecting the indices used.

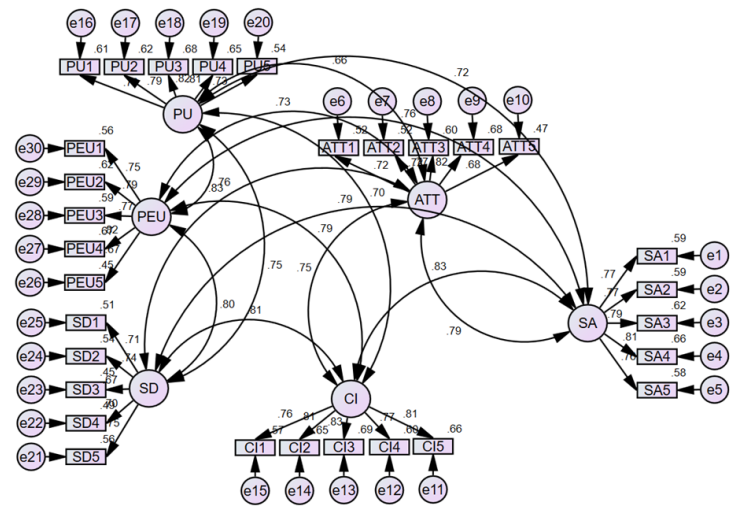

Fig. 2. Confirmatory Factor Analysis

The results of the indices indicated that $\chi 2=980.685 ;(\mathrm{p}<.05), \chi 2 / \mathrm{df}=2.466 ; \mathrm{GFI}=0.878, \mathrm{NFI}=0.903, \mathrm{TLI}=0.933 ; \mathrm{CFI}=$ 0.940 and RMSEA $=0.055$. The evaluation of the model revealed that the items considered were approximately equal or above the acceptable level of 0.9 (Bentler \& Bonnet, 1980). Similarly, $\chi 2 /$ df was higher than the recommended threshold level of 3.00, RMSEA was also high. The evaluation of the model shows that it was feasible to continue with the evaluation of study hypotheses using the Structural Equation Modeling (SEM).

\section{Structural Equation Modeling (SEM)}

The SEM analysis was conducted to evaluate the hypothesis of the research, geared towards achieving the set objective of the study. The results are presented in the figure and table below and discussed in the preceding section. 


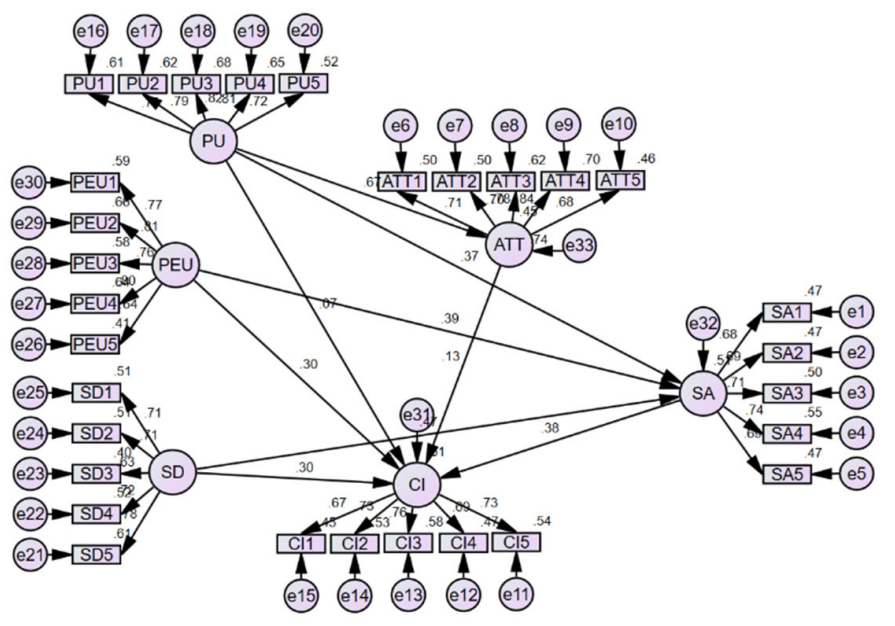

Fig. 3. Structural Equation Model Analysis

Table 2

Evaluation of Study Hypotheses

\begin{tabular}{|c|c|c|c|c|c|c|}
\hline & & & mate & S.E. & C.R. & $\mathbf{P}$ \\
\hline \multicolumn{7}{|c|}{ Direct Effects } \\
\hline ATT & $\leftarrow$ & $\mathrm{PU}$ & .619 & .053 & 11.755 & $* * *$ \\
\hline $\mathrm{SA}$ & $\leftarrow$ & SD & .338 & .037 & 9.069 & $* * *$ \\
\hline SA & $\leftarrow$ & PEU & .352 & .046 & 7.673 & $* * *$ \\
\hline SA & $\leftarrow$ & PU & .267 & .034 & 7.763 & $* * *$ \\
\hline CI & $\leftarrow$ & ATT & .116 & .050 & 2.314 & $* *$ \\
\hline CI & $\leftarrow$ & SA & .428 & .077 & 5.529 & $* * *$ \\
\hline $\mathrm{CI}$ & $\leftarrow$ & SD & .242 & .044 & 5.531 & $* * *$ \\
\hline $\mathrm{CI}$ & $\leftarrow$ & PEU & .304 & .052 & 5.869 & $* * *$ \\
\hline $\mathrm{CI}$ & $\leftarrow$ & PU & .059 & .051 & 1.171 & .242 \\
\hline \multicolumn{7}{|c|}{ Indirect Effects } \\
\hline \multicolumn{3}{|c|}{$\mathrm{CI} \leftarrow \mathrm{ATT} \leftarrow \mathrm{PU}$} & .058 & .003 & .075 & $* * *$ \\
\hline \multicolumn{3}{|c|}{$\mathrm{CI} \leftarrow \mathrm{SA} \leftarrow \mathrm{PU}$} & .040 & .002 & .118 & $* * *$ \\
\hline \multicolumn{3}{|c|}{$\mathrm{CI} \leftarrow \mathrm{SA} \leftarrow \mathrm{PEU}$} & .051 & .003 & .153 & $* * *$ \\
\hline \multicolumn{3}{|c|}{$\mathrm{CI} \leftarrow \mathrm{SA} \leftarrow \mathrm{SD}$} & .044 & .002 & .142 & $* * *$ \\
\hline
\end{tabular}

Note: $* *$ significant at $0.05, * * *$ significant at 0.01 , Perceived usefulness (PU), perceived ease ofuse (PEU), social distancing (SD), satisfac-

tion (SA), attitude (ATT) and continuous intention (CI)

The result of the study shows that Perceived Usefulness (PU) significantly and positively influences Attitude $(\mathrm{ATT})(\beta=$ $0.619, \mathrm{p}<0.01)$; and Satisfaction (SA) $(\beta=0.428, \mathrm{p}<0.01)$ but does not significantly influence Continuous Intention $(\mathrm{CI})$. The results also indicated that Perceived Ease of Use (PEU) significantly and positively influenced Satisfaction (SA) $(\beta=$ $0.352, p<0.01)$ and Continuous Intention $(C I)(\beta=0.304, p<0.01)$. Social Distancing $(S D)$ was found to have a significant and positive effect on Satisfaction (SA) $(\beta=0.338, p<0.01)$ and Continuous Intention $(\mathrm{CI})(\beta=0.242, \mathrm{p}<0.01)$. The results also revealed that satisfaction (SA) has a positive and significant influence on continuous intention to use (CI) $(\beta=0.428, p$ $<0.01)$. Attitude was also found to have had a positive and significant influence on continuous intention $(\mathrm{CI})(\beta=0.116, \mathrm{p}<$ 0.05). The study also conducted the mediation effect of attitude and satisfaction variables. The results revealed that attitude positively and significantly moderates the relationship between perceived usefulness and continuous intention to use (CI) ( $\beta$ $=0.058, \mathrm{p}<0.01)$. Additionally, Satisfaction was found to significantly and positively mediating the relationship between Perceived Usefulness and Continuous Intention to use (CI) $(\beta=0.040, p<0.01)$; Perceived Ease of Use (PEU) and Continuous Intention to use $(\mathrm{CI})(\beta=0.051, \mathrm{p}<0.01)$; and Social Distancing and Continuous Intention to use $(\mathrm{CI})(\beta=0.044, \mathrm{p}<0.01)$. These findings were significant in verifying the study hypothesis which is discussed in the following section.

\section{Discussions and conclusions}

Contagious diseases, particularly COVID-19 virus have posed a great threat to the lives of people worldwide and led to changes in the manner in which daily activities are conducted. Various measures have been adopted as a means of mitigating the spread of the virus, and the resultant infections and deaths. Among them is social distancing and avoidance of cash transactions through the adoption of digital payments. Therefore, this study sought to investigate the continuous intention to use digital payments in Thailand to prevent contagious diseases, with a particular focus on COVID-19. The findings revealed some interesting results. The age groups below 20 years and those between $20-30$ years constituted about $74.8 \%$ of the total population, which agrees with the assertion by Mondego and Gide (2020) that younger populations who are more tech-savvy are most likely to use digital payment technologies compared to the older populations in society. The results show that those 30 or under were the majority of the respondents. Correspondingly, the income group that was most represented were those with income below 15000 THB, while the least represented group were those earning above 50,000 THB. This is in 
congruence with Ferreira et al. (2020) that recognized that the use of digital payments in online retailing is usually driven by those in the lower income consumer bracket. Those in the higher income bracket are not enthusiastic about using digital payments.

The results also showed that social distancing would influence both users' Satisfaction, as well as the Continuous Intention to use digital payments. This implies that Social Distancing was a critical aspect as far as the use of digital payments is concerned in Thailand. These findings confirmed hypothesis 3 that Social Distancing (SD) has a positive influence on the continuous intention to use digital payments. Empirically, these findings infer that if Social Distancing increased by one unit, then the Satisfaction of the digital payment users would increase by 0.338 units. Similarly, the results also entail that an increase of Social Distancing by one unit would result in an increase in the Continuous Intention to use digital payment by 0.242 units. These findings reflect that of Kaur and Kushwaha (2021) whose study indicated that digital payment systems are vital in creating social distancing required to combat the spread of COVID-19. Likewise, Ağan (2020) who investigated the impact of COVID-19 pandemic process on digital payment indicated that in Turkey, the public has considered the use of digital payments such as mobile payments an effective means of keeping social distance and avoiding personal contacts.

Another interesting finding of the study was that perceived ease of use significantly and positively influenced the satisfaction of respondents using digital payment systems, as well as the continuous intention to use digital payments. This confirmed hypothesis 2 of the study that Perceived Ease of Use (PEU) has positive influences on the Continuous Intention to use digital payments. Empirically, the results implied that a one-unit increase in perceived ease of use of digital payments would result in a 0.352 unit increase in user satisfaction. As well, a one-unit increase in perceived ease of use of digital payments would result in a 0.304 unit increase in continuous intention to use digital payments. These findings are in line with other findings in Jaradat and Al-Mashaqba (2014), whose study sought to understand the adoption and usage of mobile payment services by applying the TAM3 method, findings indicated that adoption and continuous use of digital payments by the users are dependent among other variables, such as perceived ease of use. The findings were not in agreement with Altounjy et al. (2020) who found no significant influence of perceived ease of use in merchants offering mobile payment options to their customers.

Considering the Perceived Usefulness of the digital payment system, the results indicated that though it significantly and positively influenced the Attitude and Satisfaction of the users, Perceived Usefulness did not influence Continuous Intention to use digital payments by the respondents. This led to the rejection of hypothesis 1 and the conclusion that Perceived Usefulness (PU) does not have positive influences on the Continuous Intention to use digital payments. This contradicted the previous studies like Altounjy et al. (2020), Zhao and Bacao (2020), and Jaradat and Al-Mashaqba (2014). For instance, when Jaradat and Al-Mashaqba (2014) investigated the adoption and usage of mobile payment services perceived usefulness, perceived ease of use, output quality and subjective norm were among the variables that significantly influenced the use of digital payment systems. Altounjy et al. (2020) found that perceived usefulness has a significant positive impact on mobile payment acceptance while Zhao and Bacao (2020) stated the importance of perceived usefulness which indicates the degree of convenience of the use of technology to solve a problem, this, however, was found to have no significant influence on continuous intention to use digital payment methods.

The findings of the study also confirmed hypothesis 4 and hypothesis 5 . The findings indicated that a one-unit increase in Attitude would lead to a 0.116 unit increase in continuous Intention to use digital payments. Similarly, a one-unit increase in Satisfaction of the digital payment users would lead to a 0.428 unit increase in Continuous Intention to use digital payments. These findings are supported by those of Gupta, Yousaf and Mishra (2020) who investigated how pre-adoption expectancies shape post-adoption continuance intentions using an extended expectation-confirmation model. The findings of the study indicated that user Satisfaction significantly and positively influences the Continuous Intention to use. Similar findings were recorded by Gupta, Dhiman, Yousaf and Arora (2020) when investigating social comparison and continuance intention of smart fitness wearables under an extended expectation confirmation theory perspective that user satisfaction predicts the continuance intention to use which in turn leads to intention to recommend. The last aspect of the findings confirmed hypothesis 6 that attitude moderates the relationship between Perceived Usefulness and Continuous Intention to use; and hypothesis 7 indicate that Satisfaction moderates the relationship between Perceived Usefulness, Perceived Ease of Use, Social Distancing and Continuous Intention to use. The summary of the hypothesis is presented in the Table 3 .

Table 3

Summary of hypotheses model

\begin{tabular}{|c|c|c|}
\hline Hyp. & Description & Result \\
\hline H1 & Perceived usefulness (PU) has positive influences on the continuous intention to use digital payments. & Not Supported \\
\hline H2 & Perceived ease of use (PEU) has positive influences on the continuous intention to use digital payments & Supported \\
\hline H3 & Social Distancing (SD) has positive influences on the continuous intention to use digital payments & Supported \\
\hline H4 & Attitude (ATT) has positive influences on the continuous intention to use digital payments & Supported \\
\hline H5 & Satisfaction (SA) has positive influences on the continuous intentionto use digital payments & Supported \\
\hline H6 & Attitude moderates the relationship between perceived usefulness and continuous intention to use & Supported \\
\hline H7 & $\begin{array}{l}\text { Satisfaction moderates the relationship between perceived usefulness perceived ease of use social distancing and con- } \\
\text { tinuous intention to use }\end{array}$ & Supported \\
\hline H8 & Perceived usefulness (PU) has positive influences on the continuous intention to use digital payments & Not Supported \\
\hline
\end{tabular}




\section{Practical and Theoretical Implications}

The current study has several theoretical contributions. First, the work proposes the extension of the Technology Acceptance Model (TAM) to include additional variables such as attitude and user satisfaction to make the model suitable for the study. Though other studies have included satisfaction and attitude in the model, the current study model was organized in a manner that the mediating effect of attitude and satisfaction variable was evaluated. Another theoretical contribution is the extension of the existing literature regarding the use of digital payment systems in Thailand, particularly about contagious diseases such as COVID-19. Most of the studies have focused on behavioral intention to use digital payment, but this study is critical as it evaluates the continuity of use of digital payment systems. Additionally, the inclusion and evaluation of the social distancing variable have synergized with the theme of the study.

From a managerial perspective, this study provides important insights. First, the policymakers need to effectively understand the factors that influence the continuous intention to use digital payments. The use of digital payments is important in the current COVID-19 pandemic, as means of reducing physical contacts among individuals to mitigate the spread of the virus. Therefore, it is prudent for institutions providing digital payment means to evaluate the findings of this study in their decisionmaking process. Secondly, some variables have proved quite important as long as continuous use of digital payment is concerned. The satisfaction of the users with any digital payment system should be a critical consideration as long as its use is concerned. If the users are satisfied with a concerned digital payment system, then its use and continuous intention to use will be positive and vice versa. Finally, the financial institutions should consider four factors when rolling out their digital payment systems; these are, user satisfaction, attitude, perceived ease of use, and social distancing.

\section{Limitations and Future Research Directions}

This study is limited by several factors. First, the population and respondents used in this study were individuals using digital payment systems in Thailand. Thailand is a developing country and therefore huge changes are gradually taking place in its digital payment systems. Therefore, the technologies adopted in the digital payment systems currently may significantly change in future. Secondly, this study was conducted about the current COVID-19 pandemic, since the prevailing situations may change in future, the findings of this research regarding continuous intention to use digital systems should be applied with caution. Regarding future research, this study adopted the TAM model; however, future research could adopt other comprehensive models such as UTAUT in carrying out similar studies. The research also adopted the SEM model in the study and recommends future studies to adopt other techniques such as regression to compare results.

\section{Conclusions}

The purpose of this study was to investigate the continuance intention to use digital payments in Thailand to avoid contracting contagious diseases and preventing COVID-19. The study was conducted using the TAM model and adopted the SEM technique in data analysis. Several conclusions were developed from the study; one of which is that social distancing is a critical aspect as far as the use of digital payments systems is concerned because it influences continuous intention to use. Perceived Ease of Use of the digital payment system, Satisfaction and Attitude of the users influence Continuous Intention to use. Additionally, Satisfaction mediates the relationship between Perceived Usefulness, Perceived Ease of Use, Social Distancing and Continuous Intention to use. Therefore, concerned stakeholders should consider these factors when adopting and implementing digital payment systems.

\section{Acknowledgement}

This work is supported by King Mongkut's Institute of Technology Ladkrabang.

\section{References}

Ağan, B. (2020). The impact of COVID-19 pandemic process on digital payment system: Thecase of Turkey. Avrasya Sosyal ve Ekonomi Araştırmaları Dergisi, 7(7), 229 - 240

Aleem, Z. (2016, November 29). India pulled $86 \%$ of its cash out of circulation. It's not going well. Vox. https://www.vox.com/world/2016/11/29/13763070/india-modi-cash- demonetization-protests

Al-Qeisi, K. D., Dennis, C., Alamanos, E., \& Jayawardhena, C. (2014). Website design qualityand usage behavior: Unified Theory of Acceptance and Use of Technology. Journal of Business Research, 67(11), 2282-2290.

Altounjy, R., Alaeddin, O., Hussain, H., \& Kot, S. (2020). Moving from bricks to clicks: Merchants' acceptance of the mobile payment in Malaysia. International Journal of eBusiness and eGovernment Studies, 12(2), 136-150. DOI: 10.34111/ijebeg.202012204

Baber, H. (2020). Impact of FinTech on customer retention in Islamic banks of Malaysia. International Journal of Business and Systems Research, 14(2), 217 - 227.10.1504/IJBSR.2020.106279

Bentler, P.M. \& Bonett, D.G. (1980). Significance tests and goodness of fit in the analysis ofcovariance structures. Psychological Bulletin, 88, 588-606.

Chaveesuk, S., Khalid, B. \& Chaiyasoonthorn, W. (2020). Understanding stakeholders' needs forusing blockchain based smart contracts in construction industry of Thailand: Extended TAM framework', 13th International Conference on Human System Interaction (HSI). DOI: 10.1109/hsi49210.2020.9142675 
Chaveesuk, S., Khalid, B., \& Chaiyasoonthorn, W. (2021). Digital payment system innovations: A marketing perspective on intention and actual use in the retail sector. Innovative Marketing, 17(3), $109-123$. https://doi.org/10.21511/im.17(3).2021.09

Doshi, V. (2016, November 8). India withdraws 500 and 1,000 rupee notes in effort to fightcorruption. The Guardian, https:/www.theguardian.com/world/2016/nov/08/india- withdraws-500-1000-rupee-notes-fight-corruption

Ferreira, V.M.R., Parente, J., Ponchio, M.C. \& Zambaldi, F.(2020). Building loyalty in e-commerce: Does consumer income matter? International Journal of Business and Systems Research, 14(1), 74 - 94. 10.1504/IJBSR.2020.104150

Fornell, C., \& Larcker, D. F. (1981). Evaluating structural equation models with unobservable variables and measurement error. Journal of Marketing Research, 18(1), 39-50. https://doi.org/10.2307/3151312

Gupta, A., Yousaf, A., \& Mishra, A. (2020). How pre-adoption expectancies shape post-adoption continuance intentions: An extended expectation-confirmation model. International Journal of Information Management, 52, $102-094$.

Gupta, A., Dhiman, N., Yousaf, A., \& Arora, N. (2020). Social comparison and continuance intention of smart fitness wearables: An Extended Expectation Confirmation Theory Perspective. Behaviour \& Information Technology, 1-14. DOI: $10.1080 / 0144929 X .2020 .1748715$

Hsu, L., Chen, S., Chiu, M., \& Chen, J.C.H. (2015). Determinants of successful online transactions - effects of transaction assurance seal and reputation rating affecting trustand purchase intention of consumers. Human Systems Management, 34(2), 105-118. DOI: 10.3233/HSM-140827

Jaradat, M. I.-M. \& Al-Mashaqba, A.M. (2014). Understanding the adoption and usage of mobilepayment services by using TAM3. International Journal of Business Information Systems, 16(3), 271-296.

Kaur, G. \& Kushwaha, B. P. (2021). Digital payment systems a way to protect one another from coronavirus. Journal of Contemporary Issues in Business and Government, 27(1), 2381- 2388.

Khalid, B., Urbański, M., Kowalska-Sudyka, M., Wysłocka, E., \& Piontek, B. (2021). Evaluating Consumers' Adoption of Renewable Energy. Energies, 14(21), 7138. https://doi.org/10.3390/en14217138

Lanlan, Z., Ahmi, A. \& Popoola, O.M.J. (2019). Perceived ease of use, perceived usefulness and the usage of computerized accounting systems: A performance of Micro and SmallEnterprises (MSES) in China. International Journal of Recent Technology and Engineering, 8(2), 324-331.

Lin, W. R., Lin, C. \& Ding, Y. (2020). Factors affecting the behavioral intention to adopt mobile payment: An empirical study in Taiwan. Mathematics, 8(10), 1851. https://doi.org/10.3390/math8101851

Mondego, D. \& Gide, E. (2020). Exploring the factors that have impact on consumers' trust in mobile payment systems in Australia. JISTEM-Journal of Information Systems and Technology Management, 17. http://dx.doi.org/10.4301/S18071775202017009

Muangmee, C., Kot, S., Meekaewkunchorn, N., Kassakorn, N. \& Khalid, B. (2021). Factorsdetermining the behavioral intention of using food delivery apps during COVID-19 pandemics', J. Theor. Appl. Electron. Commer. Res., 16(5), 1297-1310. https://doi.org/10.3390/jtaer16050073

Najib, M. \& Fahma, F. (2020). Investigating the adoption of digital payment system through an extended Technology Acceptance Model: An insight from the indonesian small andmedium enterprises. International Journal on Advanced Science, Engineering and Information Technology, 10(4), 1702-1708.

Nathan, R.J., Victor, V., Gan, C.L. \& Kot, S. (2019). Electronic commerce for home-based businesses in emerging and developed economy. Eurasian Bus Rev, 9, 463-483. https://doi.org/10.1007/s40821-019-00124-x

Patil, P.P., Rana, N.P., \& Dwivedi, Y.K. (2018). Digital payments adoption research: a review of factors influencing consumer's attitude, intention and usage. In Al-Sharhan S. et al. (eds) Challenges and opportunities in the digital era. I3E 2018. Lecture Notes in Computer Science, 11195. Springer, Cham. https://doi.org/10.1007/978-3-030-02131- 3_6

Ray, A. D., Dhir, A., Bala, P.K. \& Kaur, P. (2019). Why do people use Food Delivery Apps (FDA)? A Uses and Gratification Theory perspective'. Journal of Retailing and Consumer Services, 51, 221-230.

Ślusarczyk, B., Tvaronavičienè, M., U1 Haque, A., \& Oláh, J. (2020). Predictors of Industry 4.0 technologies affecting logistic enterprises' performance: international perspective from economic lens. Technological and Economic Development of Economy, 26(6), 1263-1283. https://doi.org/10.3846/tede.2020.13376

Vinitha, K. \& Vasantha, S. (2017). Factors Influencing Consumer's Intention to Adopt Digital Payment-Conceptual Model. Indian Journal of Public Health Research \& Development, 8(3), 170-175.

Yang, M., Al Mamun, A., Mohiuddin, M., Nawi, N.C. \& Zaino, N.R. (2021). Cashless transactions: a study on intention and adoption of e-wallets. Sustainability, 13(2), 831. https://doi.org/10.3390/su13020831

Zhao, Y. \& Bacao, F. (2020). What factors determining customer continuingly using fooddelivery apps during 2019 novel coronavirus pandemic period? International journal of hospitality management, 91, 102683. 
(C) 2022 by the authors; licensee Growing Science, Canada. This is an open access article distributed under the terms and conditions of the Creative Commons Attribution (CC-BY) license (http://creativecommons.org/licenses/by/4.0/). 